Artigo Original / Original Paper

\title{
Sinopse de Licófitas e Samambaias do Parque Nacional da Amazônia,
} Pará, Brasil

Synopsis of the ferns and lycophytes from the Amazônia National Park, Pará, Brazil

\author{
Edson Alves Menezes ${ }^{1,4}$ \& Paulo Henrique Labiak ${ }^{1,2,3}$
}

\begin{abstract}
Resumo
Neste trabalho é apresentado um levantamento das samambaias e licófitas do Parque Nacional da Amazônia, Pará, Brasil. Este é um dos maiores Parques da bacia amazônica e agrega os principais tipos vegetacionais das terras baixas da Amazônia. Coletas foram realizadas entre 2015 e 2016, e os espécimes estão depositados no herbário INPA, UPCB e HSTM. Registrou-se 83 espécies, das quais uma é um novo registro para o Pará (Selaginella cabrerensis). As famílias com maior riqueza de espécies são Pteridaceae (19 spp.), Polypodiaceae (12 spp.), Hymenophyllaceae (8 spp.), Selaginellaceae (6 spp.) e Aspleniaceae (5 spp). Dentre os gêneros, Adiantum apresenta maior riqueza, com 13 espécies, seguido por Microgramma e Selaginella (6 spp., cada), e Asplenium e Trichomanes (5 spp., cada). A maioria das espécies é terrícola, em ambientes de terra-firme. Neste trabalho apresentamos chaves de identificação para famílias, gêneros e espécies, lista de material examinado, comentários e ilustrações.
\end{abstract}

Palavras-chave: Amazônia, biodiversidade, pteridófitas, taxonomia, terras baixas.

\begin{abstract}
We present a checklist for the ferns and lycophytes from the Amazônia National Park, Pará, Brazil. It is one of the largest National Parks in Brazil, comprising most of the vegetation types that are found in the Amazonian lowlands. This study is based on field trips carried out between 2015 and 2016. We recorded 83 species of ferns and lycophytes. All of them have been found previously in the Amazon, and one is a new occurrence for the state of Pará (Selaginella cabrerensis). The richest families are Pteridaceae (19 spp.), Polypodiaceae (12 spp.), Hymenophyllaceae (8 spp.), Aspleniaceae (5 spp.), and Selaginellaceae (6 spp.). The genus Adiantum is the richest with 13 species, followed by Microgramma and Selaginella (6 spp. each), and Asplenium and Trichomanes (5 spp. each). Most of the species occurring on terra-firme forests as terrestrial. We present identification keys to the families, genera, and species, list of specimens examined, comments and illustrations. Key words: Amazonia, biodiversity, pteridophytes, taxonomy, lowlands.
\end{abstract}

\section{Introdução}

Samambaias e licófitas constituem duas distintas linhagens, as quais compreendem as plantas vasculares de esporos livres com alternância entre as duas fases do ciclo de vida, independentes entre si, uma esporofítica e outra gametofítica (Pryer et al. 2004; Haufler et al. 2016). Ambos os grupos são bem distribuídos por todo o globo, porém com maior riqueza de espécies nas regiões tropicais do novo e do velho mundo (Tryon \& Tryon 1982; Moran 2008). No entanto, a riqueza em espécie destas plantas não é homogênea nas diversas formações vegetacionais, e é influenciada por fatores diversos, entre os quais a elevação do terreno (Tryon \& Tryon 1982; Watkins et al. 2006). No Neotrópico, os maiores

Veja material suplementar em <https://doi.org/10.6084/m9.figshare.12751925.v1>

\footnotetext{
'Instituto Nacional de Pesquisas da Amazônia, Prog. Pós-graduação em Botânica, Av. André Araújo 2936, 69067-375, Manaus, AM, Brasil.

${ }^{2}$ Universidade Federal do Paraná, Depto. Botânica, C.P. 19031, 81531-980, Curitiba, PR, Brasil.

${ }^{3}$ ORCID: <https://orcid.org/0000-0003-1803-1879>

${ }^{4}$ Autor para correspondência: menezes.inpa@gmail.com
} 
índices de diversidade concentram-se nas regiões Andinas, na Serra do Mar Brasileira, no Maciço das Guianas (tepuis) e nas montanhas da América Central e do Caribe (Moran 2008; Prado et al. 2015; Kessler 2010). Neste contexto, a Amazônia possui relevo relativamente homogêneo em grande parte de sua distribuição e, consequentemente, apresenta um número proporcionalmente menor de espécies de samambaias e licófitas, estimado em cerca de 530 espécies. (Tryon \& Conant 1975; Prado et al. 2015).

Apesar de ser uma das maiores florestas tropicais do mundo, a Amazônia é ainda uma enorme lacuna no conhecimento de sua biodiversidade. Isso pode ser observado pela baixa densidade de coletas em toda bacia amazônica, bem como na concentração destas coletas em regiões de mais fácil acesso (principais rios e estradas, ou próximos aos grandes centros) (Hopkins 2007). Para as samambaias e licófitas, particularmente, este padrão se mantém, e poucos são ainda os trabalhos que tratem da diversidade de samambaias e licófitas na Amazônia. Em geral estes trabalhos são levantamentos para regiões específicas do bioma, como aqueles realizados na região de Belém do Pará (Costa \& Pietrobom 2007, 2010), na Reserva Florestal Adolpho Ducke (Costa \& Prado 2005a, b; Freitas \& Prado 2005a; Freitas \& Windisch 2005; Prado \& Freitas 2005a, b; Prado \& Labiak 2005; Prado 2005a, b, c, d, e, f, g, h, i, j, $\mathrm{k}, 1, \mathrm{~m}, \mathrm{n}$ ), nas cangas da Serra dos Carajás (GóesNeto et al. 2016; Moura \& Salino 2016a, b; Moura et al. 2016a; Moura et al. 2016b; Salino \& Arruda 2016a, b, c, d, e; Salino et al. 2018), e na REBio Uatumã (Zuquim et al. 2008).

Considerando as dimensões da floresta amazônica e as dificuldades de acesso a todas suas regiões, levantamentos florísticos podem ser um meio para complementar estas lacunas, especialmente quando se tratam de estudos feitos em Unidades de Conservação como é o caso do Parque Nacional da Amazônia. Dessa forma, este estudo pretende apresentar o levantamento das espécies de samambaias e licófitas ocorrentes no Parque Nacional da Amazônia (PARNAAmazônia), fornecendo subsídios para a identificação das espécies por meio de chaves e ilustrações. São também apresentados comentários sobre os principais caracteres taxonômicos diagnósticos das espécies encontradas no parque, facilitando a comparação com espécies ocorrentes em outras regiões amazônicas, ainda que não tenham sido registradas para o PARNA da Amazônia.

\section{Material e Métodos}

O PARNA Amazônia (Fig. 1) está situado nas coordenadas geográficas centrais $04^{\circ} 23^{\prime} 36,01 \mathrm{~S}$ e $56^{\circ} 45^{\prime} 41,53 \mathrm{~W}$, com altitudes variando entre 100 a 200 metros. Possui uma área total de $11.144,96 \mathrm{~km}^{2}$, e seus limites se estendem sobre os municípios de Itaituba (PA), Aveiro (PA) e Maués (AM). O clima é do tipo "Ami”, segundo a classificação do Köppen (Alvares et al. 2013), com temperatura média superior a $22{ }^{\circ} \mathrm{C}$ e média anual de precipitação entre 1.750 a $2.500 \mathrm{~mm}$ (Kasecker \& Silva 2011).

Geomorfologicamente, a área encontra-se dentro do Planalto Rebaixado da Amazônia (do médio Amazonas), uma grande unidade de relevo balizada pelo Rio Tapajós. Quanto aos tipos de solos, a área compõe-se, predominantemente, de solos latossolos amarelos distróficos, que se constituem de solos envelhecidos, ácidos a muito fortemente ácidos, de boa drenagem e permeáveis (IBDF 1978). Em menor escala, registra-se a ocorrência de outros tipos de solos, como latossolos vermelhos amarelos distróficos, podzólico vermelho-amarelo, solos hidromórficos gleyzados eutróficos e distróficos, solos litólicos distróficos, areias quartzosas distróficas e solos pluviais distróficos (IBDF 1978). Nas margens do Rio Tapajós e afluentes, são ainda observadas corredeiras com afloramentos rochosos e, frequentemente, bancos de areia.

As atividades de coleta foram realizadas de outubro de 2015 a julho de 2016. Foram utilizadas as vias de acesso terrestres dentro do PARNA (BR-230, pelo Rio Tapajós, e pelo conjunto de trilhas disponíveis dentro do PARNA). O material foi coletado segundo as técnicas usuais de coletas e encontra-se depositado nos herbários INPA, UPCB e HSTM. A lista completa dos materiais examinados encontra-se no Apêndice 1 (disponibilizado no material suplementar $<$ https://doi.org/10.6084/m9.figshare.12751925. v1>). O sistema de classificação adotado segue PPG I (2016), para os níveis de família e gênero. A classificação de hábito do material examinado baseia-se nos termos propostos por Lellinger (2002). As formações vegetacionais foram classificadas em três categorias: "ambientes antropizados", "florestas de igapó" e "florestas de terra firme", sendo as duas últimas baseadas, respectivamente, na susceptibilidade natural ou não das áreas por inundações periódicas pelo Rio Tapajós e seus afluentes (Prance 1980). 


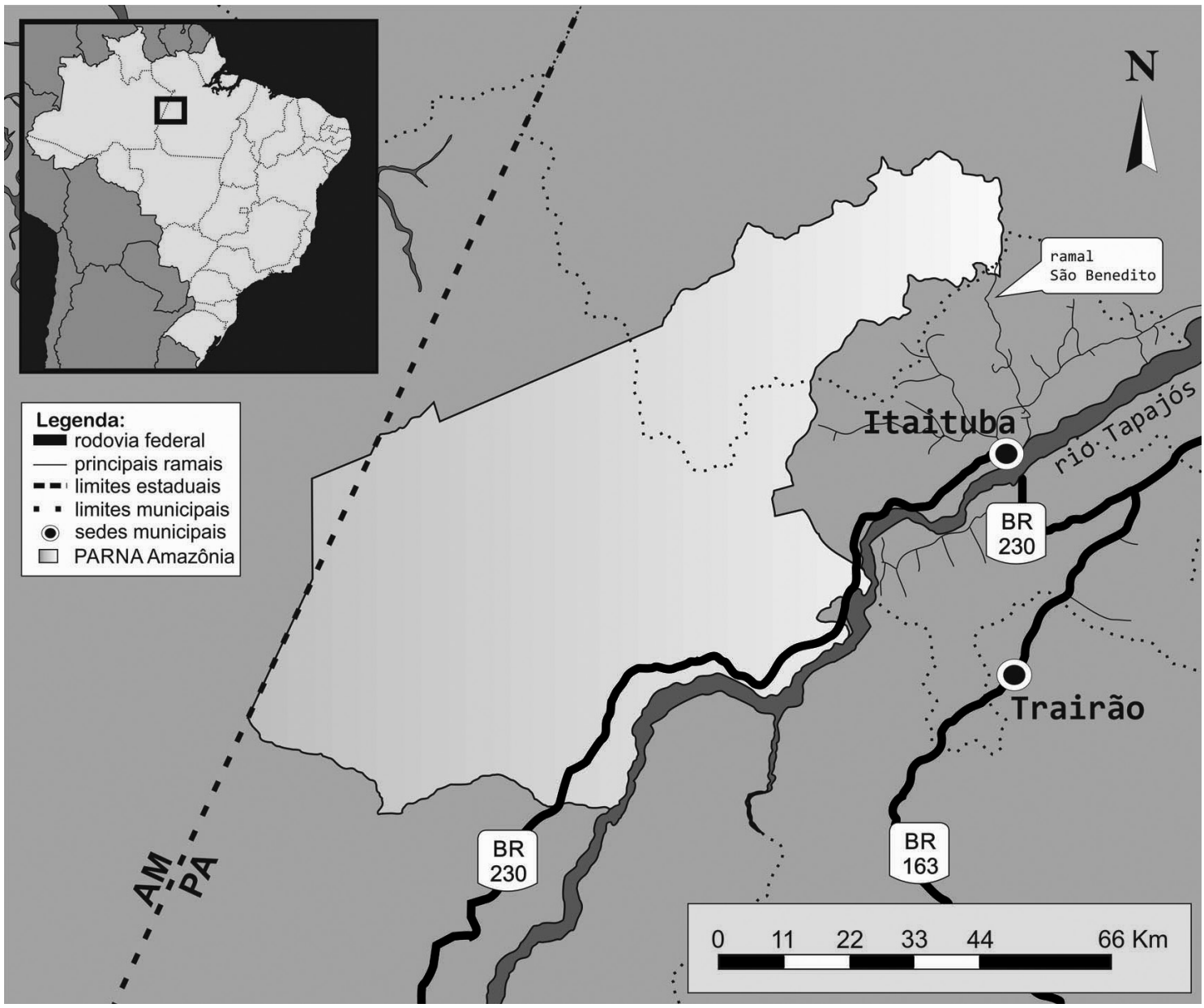

Figura 1 - Mapa mostrando a localização do Parque Nacional da Amazônia.

Figure 1 - Map showing the location of the Parque Nacional da Amazônia.

\section{Resultados e Discussão}

Registrou-se a ocorrência de 83 espécies de samambaias e licófitas, distribuídas em 22 famílias e 40 gêneros, das quais sete espécies são licófitas e 76 espécies são samambaias.

As licófitas estão representadas por duas famílias: Lycopodiaceae (Palhinhaea), com uma espécie, e Selaginellaceae (Selaginella), com seis espécies. As samambaias estão representadas por 20 famílias e 38 gêneros, sendo as famílias mais representativas Pteridaceae (19 spp.), Polypodiaceae (12 spp.), Hymenophyllaceae (9 spp.), Aspleniaceae (5 spp.) e Tectariaceae (5 spp.). Os gêneros mais ricos são: Adiantum (13 spp.), Microgramma (6 spp.), Trichomanes (6 spp.), Asplenium (5 spp.) e Triplophyllum (4 spp.).

Quanto às formas de vida, a maior parte das espécies é exclusivamente terrícola (50 spp.;
$59,5 \%)$, seguida das exclusivamente epífitas (18 spp.; 21,4\%), exclusivamente hemiepífitas (6 spp.; 7,1\%), exclusivamente rupícolas (4 spp.; $4,8 \%$ ), exclusivamente aquáticas (3 spp.; 3,6\%), terrícolas e rupícolas (2 spp.; 2,4\%) e epífitas e rupícolas (1 spp.; 1,2\%). Quanto à diversidade nos tipos vegetacionais, a maior parte das espécies é exclusiva de florestas de igapó (29 spp.; 34,5\%), seguidas por aquelas exclusivas de florestas de terra firme (24 spp.; 28,6\%), exclusivas de ambientes antropizados (11 spp.; 13,1\%), as que ocorrem em florestas de igapó e de terra firme (17 spp.; $20,2 \%$ ), em ambientes antropizados e florestas de igapó ( 2 spp.; $2,4 \%$ ) e nos três tipos vegetacionais (1 spp.; 1,2\%).

As espécies terrícolas foram as mais representativas nos três tipos vegetacionais, quando comparadas às espécies dos demais hábitos. 
Contudo, estes dados podem estar subestimados, uma vez que o esforço de coleta dos exemplares epifíticos, em grande parte, ocorreu de forma oportunista, a partir da coleta de material que caiu do dossel, ou daquilo que estava ao alcance das mãos dos coletores. Existe um considerável número de levantamentos de samambaias pela Amazônia contemplando áreas inundáveis e não inundáveis que registraram uma maior diversidade de espécies epifíticas que terrícolas (Rodrigues et al. 2004; Costa \& Pietrobom 2010; Maciel et al. 2007; Travassos et al. 2014).

Entre as espécies terrícolas, a maior parte (28 spp.) ocorre nas áreas de florestas de terra firme, sendo consequentemente menos diversas nos demais tipos vegetacionais (24 spp. nas florestas de igapó e 12 spp. nos ambientes antropizados).
Este aspecto pode estar relacionado com a baixa tolerância das samambaias terrestres de se estabelecer em ambientes suscetíveis a alagamento, conforme evidenciado, por exemplo, no trabalho de Freitas \& Prado (2005b).

Nenhuma das espécies apresentadas no presente estudo é considerada endêmica. Isto era esperado, tendo em vista que o endemismo em espécies de samambaias e licófitas na Amazônia, quando comparado a outras regiões de floresta tropical, é relativamente baixo (Tryon \& Conant 1975), principalmente devido às grandes extensões de floresta num ambiente de terras baixas e relativamente plano. E, também, nenhuma das espécies levantadas consta na lista das espécies ameaçadas de extinção (Martinelli \& Moraes 2013; SEMAS 2018).

\section{Chave de identificação das famílias de samambaias e licófitas no PARNA Amazônia}

1. Plantas com microfilos (licófitas).

2. Plantas homosporadas; folhas sem lígula Lycopodiaceae

2'. Plantas heterosporadas; folhas com lígula Selaginellaceae

1'. Plantas com megafilos (samambaias).

3. Plantas aquáticas, heterosporadas, esporângios dentro de estruturas especializadas (esporocarpos) Salviniaceae

3'. Plantas terrestres, epífitas ou rupícolas, homosporadas, esporocarpos ausentes.

4. Estípulas presentes na base do pecíolo; esporângios reunidos em sinângios, desprovidos de ânulo. Marattiaceae

4'. Pecíolo sem estípulas; esporângios separados entre si, com ânulo.

5. Esporângios sésseis ou sub-sésseis, ânulo não interrompido pelo pedicelo.

6. Ânulo apical.

7. Frondes escandentes, de crescimento indeterminado. Lygodiaceae

7'. Frondes não escandentes, de crescimento determinado Schizaeaceae

6'. Ânulo oblíquo.

8. Soros marginais, esporos com clorofila Hymenophyllaceae

8'. Soros abaxiais, esporos sem clorofila.

9. Frondes pseudodicotomicamente pinadas, comumente escandentes ....... Gleicheniaceae

9'. Frondes pinadas ou mais divididas, não escandentes.

10. Plantas arborescentes; pecíolo com escamas, às vezes com tricomas e/ou espinhos Cyatheaceae

10'. Plantas herbáceas; pecíolo sem tricomas, escamas e espinhos Metaxyaceae

5'. Esporângios pedicelados, ânulo vertical, interrompido pelo pedicelo.

11. Base do pecíolo articulada com o rizoma Polypodiaceae

11'. Pecíolo não articulado com o rizoma, ou articulado acima da base do pecíolo.

12. Pecíolo com 2 feixes vasculares na base.

13. Escamas clatradas; soros lineares.

13'. Escamas não-clatradas; soros arredondados a alongados (não lineares) ou acrosticoides .Thelypteridaceae

12'. Pecíolo com 1, 3 ou mais feixes vasculares na base. 
14. Soros alongados a lineares, subcostais e paralelos à costa Blechnaceae

14'. Soros arredondados, cônicos ou alongados e oblíquos à costa, ou lineares, submarginais e paralelos à margem foliar ou esporângios formando soros acrosticoides.

15. Lâmina inteira a pinatífida ou furcada, ou 1-pinada com pinas não dimidiadas.

16. Frondes inteiras ou raramente furcadas na porção apical; indúsios de origem abaxial ausentes Pteridaceae (vitarioides)

16'. Frondes 1-pinada; indúsios de origem abaxial presentes.

17. Frondes monomorfas; soros formando 1 fileira entre a costa e a lâmina, nunca acrosticóides Nephrolepidaceae

17'. Frondes dimorfas ou monomorfas, se monomorfas, soros formando 2 ou mais fileiras entre a costa e a lâmina, acorstcóides. Lomariopsidaceae

15'. Lâmina 1-2-pinadas, com pinas dimidiadas, ou 1-4 pinado-pinatífidas.

18. Soros lineares, marginais a sub-marginais.

19. Margem da lâmina revoluta, modificada em pseudoindúsio.

20. Esporos monoletes

20'. Esporos triletes Dennstaedtiaceae (Pteridium)

19'. Margem da lâmina plana, não modificada em pseudoindusio.

21. Indúsios lineares, paralelos à margem da lâmina, no ápice de duas ou mais nervuras

Lindsaeaceae

21'. Indúsios cônicos, no ápice de uma única nervura Saccolomataceae

18'. Soros arredondados ou esporângios dispersos ao longo das nervuras, abaxiais.

22. Epiderme abaxial com revestimento farináceo; esporângios distribuídos ao longo das nervuras .Pteridaceae (Pityrogramma)

22'. Epiderme abaxial sem revestimento farináceo; soros arredondados.

23. Raque, costa e cóstula conspicuamente sulcadas adaxialmente, sulcos decorrentes entre si; indúsio peltado ou ausente.

.Dryopteridaceae

23'. Raque, costa e cóstula não ou levemente sulcadas, sulcos não decorrentes entre si; indúsio reniforme Tectariaceae

Lycopodiaceae Mirb.

Palhinhaea cernua (L.) Vasc. \& Franco.

Fig. 2a-b

Material examinado selecionado: Menezes \& Nascimento 234 (INPA, UPCB).
Palhinhaea cernua ocorre como terrícola, em ambiente antropizado.

Selaginellaceae Willk.

\section{Chave de identificação das espécies de Selaginella}

1. Caule articulado.

2. Microfilos laterais biauriculados; microfilos axilares com duas aurículas conspícuas Selaginella conduplicata

2'. Microfilos laterais com uma aurícula; microfilos axilares com base truncada, podendo apresentar duas aurículas inconspícuas Selaginella parkeri

1'. Caule não-articulado.

3. Caule ereto; rizóforos restritos à porção subterrânea do caule Selaginella radiata

3'. Caule prostrado; rizóforos acima da metade superior do caule, por vezes por todo o caule.

4. Microfilos dorsais com margem serrada .... Selaginella producta

4'. Microfilos dorsais com margem ciliada, ao menos no $1 / 3$ basal.

5. Microfilos dorsais com ápice longo-aristado; microfilos laterais com superfície superior sem idioblastos. Selaginella breynii

5'. Microfilos dorsais com ápice agudo a cuneado; microfilos laterais com superfície superior sem idioblastos Selaginella cabrerensis 



Figura 2 - a-b. Palhinhaea cernua - a. ramos férteis; b. esporofilos. c-d. Selaginella breynii - c. hábito; d. microfilos com ápice aristado e margem ciliada. e-f. S. cabrerensis -e. hábito; f. microfilos com ápice agudo. g-h. S. conduplicata - g. hábito; h. base dos microfilos laterais bi-auriculados. i-j. S. parkeri-i. hábito; j. base dos microfilos laterais com uma aurícula. k-1. S. producta - k. hábito; 1. microfilos dorsais com margem dentada. m-n. S. radiata - m. hábito; n. microfilos dorsais aristados. o-p. Asplenium angustum - o. hábito; p. disposição dos soros. q-r. A. cristatum - q. hábito; r. últimos segmentos. s-t. A. cruegeri - s. hábito; t. pínulas férteis.

Figure 2 - a-b. Palhinhaea cernua - a. fertile branches; b. sporophylls. c-d. Selaginella breynii - c. habit; d. microphylls. e-f. $S$. cabrerensis - e. habit; f. microphylls. g-h. S. conduplicata - g. habit; h. lateral microphylls. i-j. S. parkeri-i. habit; j. lateral microphylls. k-1. S. producta - k. habit; 1. dorsal microphylls. m-n. S. radiata - m. habit; n. dorsal microphylls. o-p. Asplenium angustum - o. habit; p. sori. q-r. A. cristatum - q. habit; r. fertile segments. s-t. A. cruegeri - s. habit; t. fertile pinnules. 
Selaginella breynii Spring.

Fig. $2 \mathrm{c}-\mathrm{d}$

Material examinado: Menezes \& Nascimento Filho 65 (INPA, UPCB).

Selaginella breynii ocorre como terrícola, em florestas de igapó.

Selaginella cabrerensis Hieron.

Fig. 2e-f

Material examinado: Menezes et al. 334 (UPCB).

Selaginella cabrerensis ocorre como rupícola, em florestas de igapó.

\section{Selaginella conduplicata Spring. $\quad$ Fig. $2 \mathrm{~g}-\mathrm{h}$} Material examinado selecionado: Menezes et al. 286 (UPCB).

Selaginella conduplicata ocorre como terrícola, em florestas de igapó e de terra firme.

Selaginella parkeri (Hook. \& Grev.) Spring.

Fig. $2 i-j$
Material examinado selecionado: Menezes \& Nascimento Filho 56 (INPA).

Selaginella parkeri ocorre como terrícola e rupícola, em florestas de igapó e de terra firme.

Selaginella producta Baker.

Fig. 2k-1

Material examinado: Menezes \& Nascimento 168 (INPA).

Selaginella producta ocorre como terrícola, em florestas de igapó e de terra firme.

Selaginella radiata (Aubl.) Baker.

Fig. $2 m-n$

Material examinado: Menezes et al. 321 (UPCB).

Selaginella radiata ocorre como terrícola, em florestas de terra firme.

Aspleniaceae Newman

\section{Chave de identificação das espécies de Asplenium}

1. Lâminas simples; plantas epífitas.

2. Ápice atenuado, soros medindo aprox. $3 / 4$ do comp. da nervura Asplenium angustum

2'. Ápice acuminado, soros medindo aprox. 1/3 a 1/2 do comp. da nervura ......Asplenium angustum

1'. Lâmina 1-pinada ou mais dividida; plantas terrícolas.

3. Lâmina 2-pinada Asplenium cristatum

3'. Lâmina 1-pinada.

4. Ápice das pinas laterais em geral obtuso Asplenium cruegeri

4'. Ápice das pinas laterais em geral agudo Asplenium hostmanii

Asplenium angustum Sw.

Fig. 2o-p

Material examinado selecionado: Menezes et al. 295 (UPCB).

Asplenium angustum ocorre como epífita, em florestas de igapó e de terra firme.

Asplenium cristatum Lam.

Fig. 2q-r

Material examinado: Menezes \& Nascimento 102 (INPA).

Asplenium cristatum ocorre como terrícola, em florestas de terra firme.

Asplenium cruegeri Hieron.

Fig. 2s-t

Material examinado selecionado: Menezes \& Nascimento Filho 57 (INPA).

Asplenium cruegeri ocorre como terrícola, em florestas de terra firme.
Asplenium hostmanii Hieron.

Fig. 3a-b Material examinado: Menezes \& Nascimento Filho 87 (INPA). Asplenium hostmanii ocorre como terrícola, em florestas de terra firme.

Asplenium serratum L.

Fig. $3 \mathrm{c}-\mathrm{d}$

Material examinado selecionado: Menezes \& Nascimento 113 (INPA).

Asplenium serratum ocorre como epífita, em florestas de igapó e de terra firme.

Blechnaceae Newman

Telmatoblechnum serrulatum (Rich.) Perrie, D.J.Ohlsen \& Brownsey. Fig. $3 \mathrm{e}-\mathrm{f}$ Material examinado: Menezes \& Almeida 324 (UPCB). 

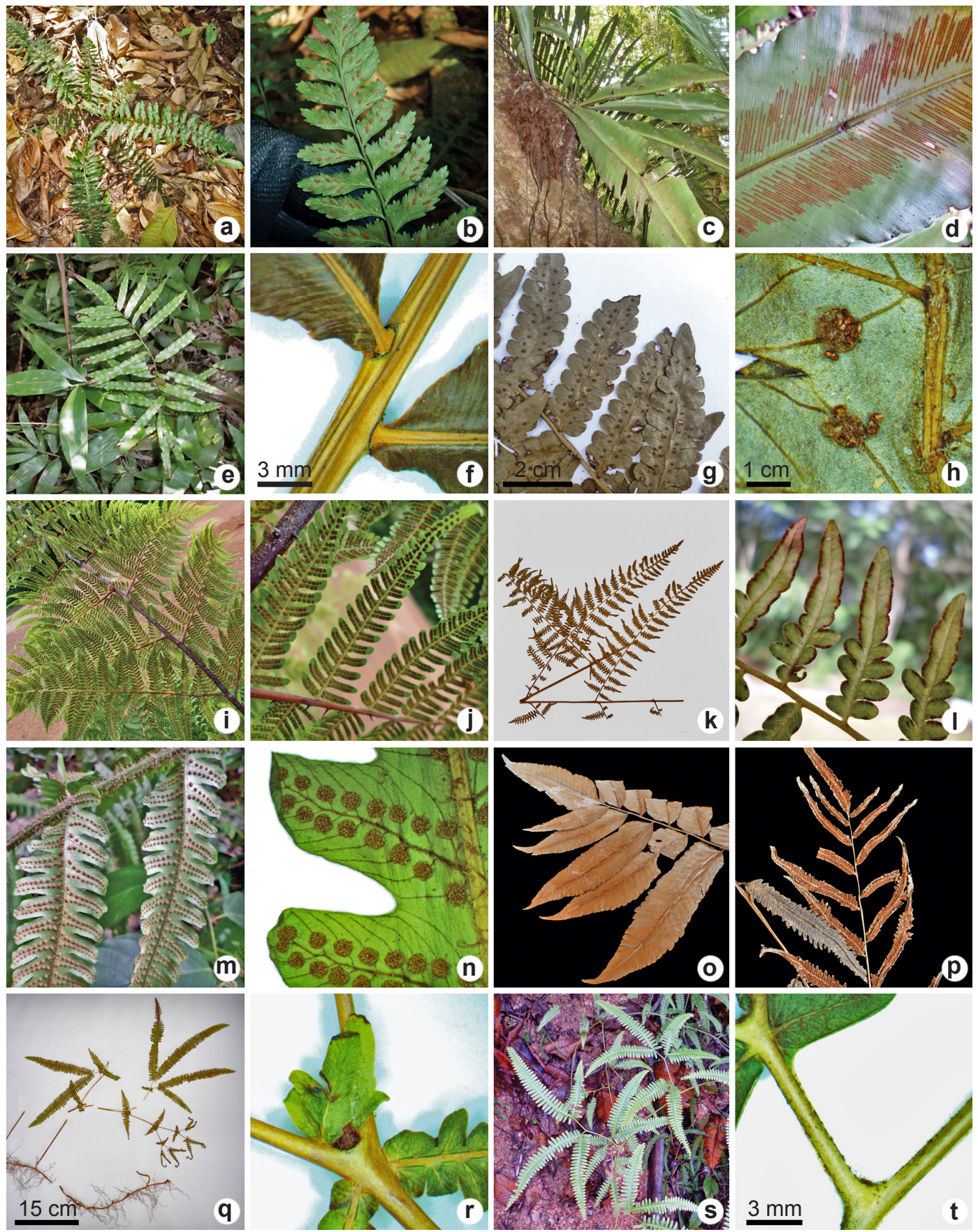

Figura 3 - a-b. Asplenium hostmannii - a. hábito; b. pínulas férteis. c-d. A. serratum - c. hábito; d. disposição dos soros. e-f. Telmatoblechnum serrulatum - e. hábito; f. pinas articuladas. g-h. Cyathea cyatheoides - g. ápice das pinas; h. pínulas. i-j. C. microdonta - i. superfície abaxial das pinas; j. raque e pínulas. k-1. Pteridium arachnoideum - k. pinas; 1. pínulas. m-n. Ctenitis refulgens - m. pinas; $\mathrm{n}$. disposição dos soros e das nervuras. o-p. Cyclodium meniscioides var. meniscioides - o. ápice da fronde estéril; p. ápice da fronde fértil. q-r. Dicranopteris flexuosa - q. bifurcações da raque com pinas acessórias; r. pinas acessórias. s-t. Gleichenella pectinata - s. hábito; t. bifurcações da raque. Figure 3 - a-b. Asplenium hostmannii - a. habit; b. fertile pinnules. c-d. A. serratum - c. habit; d. sori. e-f. Telmatoblechnum serrulatum - e. habit; f. pinnae articulation. g-h. Cyathea cyatheoides - g. pinna apex; h. pinnules. i-j. C. microdonta - i. pinnae; j. rachis showing the spines. k-1. Pteridium arachnoideum - k. pinnae; 1. pinnules. m-n. Ctenitis refulgens - m. pinnae; n. sori and veins. o-p. Cyclodium meniscioides var. meniscioides - o. apex of the sterile frond; p. apex of the fertile frond. q-r. Dicranopteris flexuosa - q. bifurcations with assessory pinnae; r. assessory pinnae. s-t. Gleichenella pectinata $-\mathrm{s}$. habit; t. rachis bifurcation. 
Telmatoblechnum serrulatum ocorre em ambientes paludosos em florestas de igapó.

\section{Cyatheaceae Kaulf.}

\section{Chave de identificação das espécies de Cyathea}

1. Raque e costa sem espinhos; soros indusiados Cyathea cyatheoides

1'. Raque e costa frequentemente com espinhos; soros não indusiados Cyathea microdonta

Cyathea cyatheoides (Desv.) K.U.Kramer.

Fig. 3g-h

Material examinado: Menezes \& Nascimento 169 (INPA).

Cyathea cyatheoides é uma planta arborescente e ocorre como terrícola, em florestas de igapó.

Cyathea microdonta (Desv.) Domin.

Fig. 3i-j

Material examinado selecionado: Menezes \& André 333 (UPCB).
Cyathea microdonta é uma planta arborescente e ocorre como terrícola, em florestas de igapó.

\section{Dennstaedtiaceae Losty \\ Pteridium arachnoideum (Kaulf.) Maxon.}

Fig. 3k-1

Material examinado selecionado: Menezes et al. 298 (UPCB).

Pteridium arachnoideum ocorre como terrícola, em ambientes antropizados.

Dryopteridaceae Herter

\section{Chave de identificação dos gêneros de Dryopteridaceae}

1. Nervuras livres; frondes monomorfas Ctenitis

1'. Nervuras anastomosadas; frondes dimorfas ou monomorfas Cyclodium

Ctenitis refulgens (Klotzsch ex Mett.) C.Chr. ex Vareschi.

Fig. 3m-n

Material examinado selecionado: Menezes et al. 310 (UPCB).

Ctenitis refulgens ocorre como terrícola, em florestas de terra firme.
Cyclodium meniscioides (Willd.) C.Presl var. meniscioides.

Fig. 3o-p

Material examinado: Menezes \& Nascimento 177 (INPA).

Cyclodium meniscioides ocorre como hemiepífita, em florestas de igapó.

\section{Gleicheniaceae C.Presl}

\section{Chave de identificação dos gêneros de Gleicheniaceae}

1. Pinas regularmente furcadas, simétricas; pinas acessórias presentes nas bifurcações......Dicranopteris

1'. Pinas irregularmente furcadas, assimétricas; pinas acessórias ausentes nas bifurcações ... Gleichenella

Dicranopteris flexuosa (Schrad.) Underw.

Fig. 3q-r

Material examinado: Menezes \& Nascimento 242 (INPA).

Dicranopteris flexuosa ocorre como terrícola, em ambientes antropizados.
Gleichenella pectinata (Willd.) Ching. Fig. 3s-t Material examinado selecionado: Menezes et al. 294 (UPCB).

Gleichenella pectinata ocorre como terrícola, em ambientes antropizados.

Hymenophyllaceae Gaudich.

\section{Chave de identificação dos gêneros de Hymenophyllaceae}

1. Raízes ausentes; plantas geralmente epífitas. Didymoglossum

1'. Raízes presentes; plantas geralmente terrícolas Trichomanes 


\section{Chave de identificação das espécies de Didymoglossum}

1. Margem da lâmina glabra; invólucro completamente inserido na lâmina Didymoglossum sp.

1'. Margem da lâmina com tricomas, simples a estrelados; invólucro não ou parcialmente inseridos na lâmina.

2. Tricomas da margem foliar simples ou bífidos

Didymoglossum krausii

2'. Tricomas da margem foliar estrelados Didymoglossum punctatum subsp. labiatum

Didymoglossum krausii (Hook. \& Grev.) C.Presl.

Fig. 4a-b

Material examinado: Menezes et al. 335 (UPCB).

Didymoglossum krausii ocorre como epífita, em florestas de igapó.

Didymoglossum punctatum (Poir.) Desv. subsp. labiatum (Jenman) Wess. Boer.

Fig. $4 \mathrm{c}-\mathrm{d}$

Material examinado: Menezes et al. 336 (UPCB).
Didymoglossum punctatum ocorre como epífita, em florestas de igapó.

Didymoglossum sp.

Fig. 4e-f

Material examinado: Menezes et al. 313 (UPCB).

Este espécime ocorre como epífita, em florestas de terra firme. Se parece a Didymoglossum godmanii, mas estudos adicionais são ainda necessários para uma identificação mais precisa deste material.

\section{Chave de identificação das espécies de Trichomanes}

1. Frondes monomorfas.

2. Lâmina 2 ou mais pinada Trichomanes elegans

2'. Lâmina 1-pinada.

3. Hemiepífitas; frondes adpressas ao substrato. Trichomanes ankersii

3'. Terrícolas; frondes não adpressas ao substrato Trichomanes hostmannianum

1'. Frondes dimorfas.

4. Fronde fértil pinada Trichomanes pinnatum

4'. Fronde fértil simples.

5. Fronde estéril decumbente; invólucro exserto Trichomanes vittaria

5'. Fronde estéril ereta; invólucro inserido na lâmina Trichomanes trollii

Trichomanes ankersii C.S.Parker ex Hook. \& Grev. Fig. 4g-h Material examinado selecionado: Menezes \& Nascimento 166 (INPA).

Trichomanes ankersii ocorre como hemiepífita, em florestas de igapó.

Trichomanes elegans Rich.

Fig. $4 \mathrm{i}-\mathrm{j}$ Material examinado: Menezes \& Nascimento 173 (INPA).

Trichomanes elegans ocorre como terrícola, em florestas de igapó.

\section{Trichomanes hostmannianum (Klotzsch)} Kunze.

Material examinado selecionado: Menezes \& Nascimento 265 (INPA).

Trichomanes hostmannianum ocorre como terrícola, em florestas de igapó.
Trichomanes pinnatum Hedw.

Fig. $4 m-n$ Material examinado selecionado: Menezes \& Nascimento Filho 58 (INPA).

Trichomanes pinnatum ocorre como terrícola, em ambientes antropizados, florestas de igapó e de terra firme.

Trichomanes trollii Bergdolt.

Fig. 4o-p Material examinado: Menezes \& Nascimento 171 (INPA).

Trichomanes trollii ocorre como rupícola, em florestas de igapó.

Trichomanes vittaria DC. ex Poir. Fig. 4q-r Material examinado selecionado: Menezes \& Nascimento 124 (INPA).

Trichomanes vittaria ocorre como terrícola, em ambientes antropizados, florestas de igapó e de terra firme. 



Figura 4 - a-b. Didymoglossum krausii - a. frondes; b. disposição dos soros. c-d. D. punctatum subsp. labiatum - c. fronde fértil (à esq.) e estéril (à dir.); d. invólucros labiados, com margem nigrescente. e-f. Didymoglossum sp. - e. fronde fértil; f. margem glabra, nervuras livres. g-h. Trichomanes ankersii - g. hábito; h. superfície adaxial da lâmina fértil. i-j. T. elegans - i. superfície adaxial da pina; j. últimos segmentos e disposição dos soros (superfície adaxial). k-1. T. hostamannianum - k. hábito; 1. lâmina fértil (superfície adaxial). m-n. T. pinnatum - m. fronde fértil e estéreis; n. disposição dos soros. o-p. Trichomanes trollii - o. hábito; p. soros imersos na lâmina. q-r. T. vittaria - q. hábito; r. fronde fértil (à esq.) e estéreis (à dir.). s-t. Lindsaea falcata - s. pina (superfície adaxial); t. pina (superfície abaxial). Figure 4 - a-b. Didymoglossum krausii - a. fronds; b. sori. c-d. D. punctatum subsp. labiatum - c. fertile and sterile fronds; d. involucres with blackish margins. e-f. Didymoglossum sp. - e. fertile frond; f. margin and free veins. g-h. Trichomanes ankersii-g. habit; $h$. adaxial side of a fertile lamina. $\mathrm{i}-\mathrm{j}$. T. elegans - i. adaxial side of a pinna; j. ultimate segments and sori. k-1. T. hostamannianum - k. habit; 1. fertile lamina. m-n. T. pinnatum - m. fertile and sterile fronds; n. sori. o-p. Trichomanes trollii - o. habit; p. sori. q-r. T. vittaria - q. habit; r. fertile and sterile fronds. s-t. Lindsaea falcata - s. adaxial side of a pinna; t. abaxial side of a pinna. 
Lindsaeaceae C.Presl

\section{Chave de identificação das espécies de Lindsaea}

1. Pinas distais não ou levemente reduzidas, pina apical maior que as demais, deltoide, com base assimétrica, 3-15 pares de pínulas por pina. Lindsaea falcata

1’. Pinas distais e terminais gradualmente reduzidas, mais de 25 pares de pinas por pina

Lindsaea stricta var. stricta

Lindsaea falcata Dryand.

Fig. $4 \mathrm{~s}-\mathrm{t}$

Material examinado: Menezes et al. 303 (UPCB).

Lindsaea falcata ocorre como terrícola, em florestas de igapó.
Lindsaea stricta (Sw.) Dryand. var. stricta.

Fig. 5a-b

Material examinado selecionado: Menezes \& Nascimento Filho 191 (INPA).

Lindsaea stricta var. stricta ocorre como terrícola, em ambientes antropizados.

\section{Lomariopsidaceae Alston}

\section{Chave de identificação dos gêneros de Lomariopsidaceae:}

1. Plantas terrícolas; frondes monomorfas, soros arredondados Cyclopeltis

1'. Plantas hemiepífitas; frondes dimorfas, soros acrosticoides. Lomariopsis

Cyclopeltis semicordata (Sw.) J.Sm. Fig. 5c-d Material examinado selecionado: Menezes et al. 318 (UPCB).

Cyclopeltis semicordata ocorre como terrícola, em florestas de terra firme.

Lomariopsis prieuriana Fée.

Fig. 5e-f
Material examinado selecionado: Menezes \& Nascimento 179 (INPA).

Lomariopsis prieuriana ocorre como hemiepífita, em florestas de igapó e de terra firme.

Lygodiaceae M.Roem.

\section{Chave de identificação das espécies de Lygodium}

1. Pínulas estéreis lobadas na base, as distais em geral menores que as proximais.... Lygodium venustum

1'. Pínulas estéreis inteiras, raramente com lóbulos basais, as distais e proximais aproximadamente do mesmo tamanho Lygodium volubile

Lygodium venustum $\mathrm{Sw}$.

Fig. 5g-h

Material examinado selecionado: Menezes \& Nascimento 262 (INPA).

Lygodium venustum ocorre como hemiepífita, em ambientes antropizados.

\section{Lygodium volubile $\mathrm{Sw}$.}

Fig. 5i-j

Material examinado: Menezes \& Nascimento Filho 219 (INPA).
Lygodium volubile ocorre como hemiepífita, em ambientes antropizados e florestas de igapó.

Marattiaceae Kaulf.

Danaea leprieurii Kunze.

Fig. $5 \mathrm{k}-1$

Material examinado: Menezes \& Nascimento 174 (INPA).

Danaea leprieurii ocorre como terrícola, em florestas de igapó. 

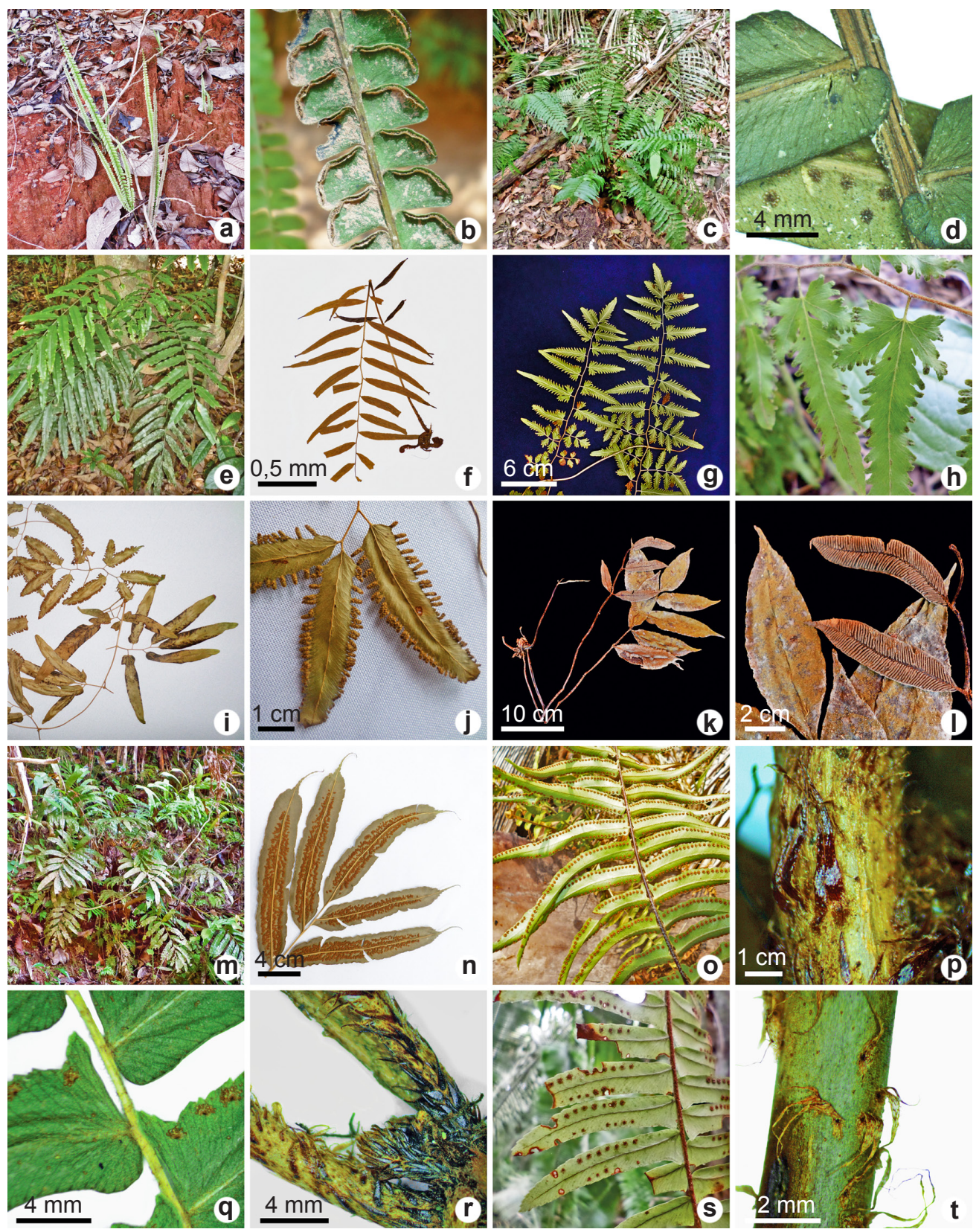

Figura 5 - a-b. Lindsaea stricta var. stricta - a. hábito; b. pínulas (superfície abaxial). c-d. Cyclopeltis semicordata - c. hábito; d. base basiscópica da pina sobrepondo a raque. e-f. Lomariopsis prieuriana - e. hábito; f. fronde fértil (superfície abaxial). g-h. Lygodium venustum - g. pinas férteis (superfície abaxial); h. pínulas férteis lobadas (superfície adaxial). i-j. L. volubile - i. pinas férteis e estéreis; j. pínulas férteis (superfície abaxial). k-1. Danaea leprieurii - k. pina fértil e estéril; 1. pínulas férteis e estéreis. m-n. Metaxya parkeri $-\mathrm{m}$. hábito; $\mathrm{n}$. pinas férteis. o-p. Nephrolepis biserrata - o. pínulas; p. escamas não adpressas da base do pecíolo. q-r. N. brownii - q. raque e base das pínulas (superfície abaxial); r. escamas adpressas da base do pecíolo. s-t. N. rivularis - s. pínulas; t. escamas de base pectinadas da base do pecíolo.

Figure 5 - a-b. Lindsaea stricta var. stricta - a. habit; b. abaxial side of the pinnules. c-d. Cyclopeltis semicordata $-\mathrm{c}$. habit; d. base of the pinna overlapping the rachis. e-f. Lomariopsis prieuriana - e. habit; f. abaxial side of a fertile frond. $\mathrm{g}$-h. Lygodium venustum - $\mathrm{g}$. abaxial side of a fertile pinna; $h$. adaxial side of a fertile pinna. $\mathrm{i}-\mathrm{j}$. L. volubile $-\mathrm{i}$. fertile and sterile pinnae; $j$. abaxial side of fertile pinnae. $\mathrm{k}-1$. Danaea leprieurii - k. fertile and sterile pinnae; 1 . fertile and sterile pinnae. $\mathrm{m}-\mathrm{n}$. Metaxya parkeri $-\mathrm{m}$. habit; $\mathrm{n}$. fertile pinnae. o-p. Nephrolepis biserrata - o. pinnules; p. scales at the petiole base. q-r. N. brownii - q. adaxial side of the rachis and base of the pinnules; r. appressed scales at the petiole bases. s-t. N. rivularis - s. pinnules; t. scales at the petiole bases. 
Metaxyaceae Pic.Serm.

Metaxya parkeri (Hook. \& Grev.) J.Sm.

Fig. $5 \mathrm{~m}-\mathrm{n}$

Material examinado selecionado: Menezes \& Nascimento Filho 209 (INPA).
Metaxya parkeri ocorre como terrícola, em ambientes antropizados.

Nephrolepidaceae Pic.Serm.

\section{Chave de identificação das espécies de Nephrolepis}

1. Escamas do rizoma e pecíolo adpressas..... Nephrolepis brownii

1'. Escamas do rizoma e pecíolo não adpressas.

2. Base da pina equilátera ou levemente assimétrica Nephrolepis biserrata

2'. Base da pina inequilátera, nitidamente assimétrica Nephrolepis rivularis

Nephrolepis biserrata (Sw.) Schott.

Fig. 5o-p

Material examinado: Menezes \& Nascimento Filho 62 (INPA).

Nephrolepis biserrata ocorre como terrícola, em ambientes antropizados e florestas de igapó.

Nephrolepis brownii (Desv.) Hovenkamp \& Miyam.

Fig. 5q-r

Material examinado selecionado: Menezes \& Nascimento 240 (INPA).
Nephrolepis brownii ocorre como terrícola, em ambientes antropizados.

Nephrolepis rivularis (Vahl) Mett ex Krug.

Fig. $5 \mathrm{~s}-\mathrm{t}$

Material examinado: Menezes \& Nascimento 131 (INPA).

Nephrolepis rivularis ocorre como epífita, em florestas de terra firme.

Polypodiaceae J.Presl \& C.Presl

\section{Chave de identificação dos gêneros de Polypodiaceae}

1. Lâmina inteira.

2. Soros formando mais que 2 fileiras entre a costa e a margem

Campyloneurum

2'. Soros formando uma única fileira entre a costa e a margem.

3. Escamas do rizoma não clatradas

Microgramma

3'. Escamas do rizoma clatradas a sub-clatradas.

Pleopeltis

1'. Lâmina pinatissecta a 1-pinada.

4. Nervuras livres, escamas basifixas...

Pecluma

4'. Nervuras anastomosadas, escamas peltadas.

5. Lâmina pinatissecta, soros na junção entre duas vênulas inclusas

Phlebodium

5'. Lâmina pinatissecta a 1-pinada, soros no ápice de uma única vênula inclusa....Serpocaulon

\section{Chave de identificação das espécies de Campyloneurum}

1. Aréolas primárias divididas, rizoma mais que $3 \mathrm{~mm}$ de larg.

Campyloneurum phyllitidis

1'. Aréolas primárias não-divididas, rizoma $3 \mathrm{~mm}$ de larg. ou menos .Campyloneurum repens

Campyloneurum phyllitidis (L.) C.Presl.

Fig. 6a-b

Material examinado selecionado: Menezes \& Nascimento Filho 61 (INPA).

Campyloneurum phyllitidis ocorre como hemiepífita, em florestas de igapó e de terra firme.
Campyloneurum repens (Aubl.) C.Presl.

Fig. 6c-d

Material examinado selecionado: Menezes \& Nascimento Filho 51 (INPA).

Campyloneurum repens ocorre como hemiepífita, em florestas de terra firme. 

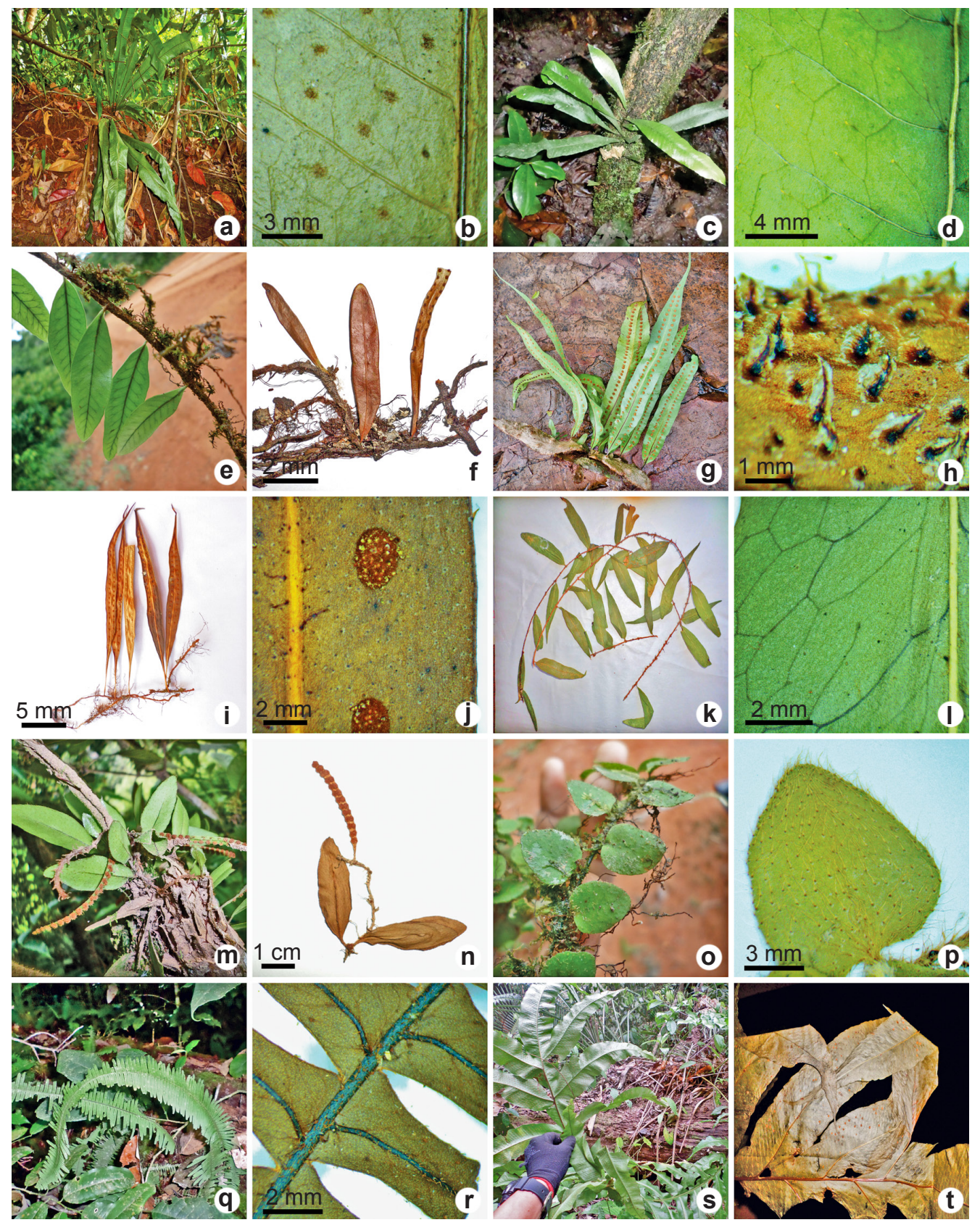

Figura 6 - a-b. Campyloneurum phyllitidis - a. hábito; b. disposição dos soros e das nervuras. c-d. C. repens - c. hábito; d. disposição dos soros e das nervuras. e-f. Microgramma baldwinii - e. frondes estéreis; f. frondes estéril (à esq.) e fértil (à dir.). g-h. M. megalophylla - g. fronde; h. escamas do rizoma. i-j. M. percussa - i. lâmina (superfície abaxial); j. escamas arredondadas na superfície abaxial da lâmina. k-1. M. persicariifolia $-\mathrm{k}$. fondes; 1. disposição das nervuras (superfície abaxial). m-n. M. reptans $-\mathrm{m}$. hábito; $\mathrm{n}$. soros sobrepondo a margem da lâmina (superfície abaxial). o-p. M. tecta var. nana - o. lâmina; p. escamas filiformes de base orbicular sobre a lâmina (superfície adaxial). q-r. Pecluma plumula - q. hábito; r. disposição das nervuras (superfície abaxial). s-t. Phlebodium decumanum - s. hábito; t. lâmina fértil (superfície abaxial).

Figure 6 - a-b. Campyloneurum phyllitidis - a. habit; b. sori and veins. c-d. C. repens - c. habit; d. sori and veins. e-f. Microgramma baldwinii-e. sterile pinnae; f. fertile and sterile pinnae. g-h. M. megalophylla-g. pinnae; h. rhizome scales. i-j. M. percussa-i. abaxial side of the lamina; j. scales from the abaxial side of the lamina. k-1. M. persicariifolia - k. pinnae; 1 . abaxial side showing the veins. m-n. M. reptans - m. habit; n. sori. o-p. M. tecta var. nana - o. pinnae; p. filiforme scales. q-r. Pecluma plumula - q. habit; r. veins. s-t. Phlebodium decumanum - s. habit; t. fertile pinna. 


\section{Chave de identificação das espécies de Microgramma}

1. Superfície laminar da lâmina estéril revestida abaxial e/ou adaxialmente por escamas arredondadas .. Microgramma percussa

1'. Superfície laminar da lâmina estéril revestida abaxial e/ou adaxialmente por escamas subuladas.

2. Frondes dimorfas.

3. Soros frequentemente se projetando além da margem da fronde, visíveis na face adaxial da fronde Microgramma reptans

3'. Soros totalmente inseridos na face abaxial da fronde fértil, não visíveis na face adaxial da fronde fértil. Microgramma nana

2'. Frondes monomorfas a sub-dimorfas.

4. Rizomas nitidamente achatados

4'. Rizomas cilíndricos.

5. Soros arredondados Microgramma megalophylla

5'. Soros oblongos Microgramma baldwinii Microgramma persicariifolia

Microgramma baldwinii Brade.

Fig. 6e-f Material examinado selecionado: Menezes et al. 272 (UPCB).

Microgramma baldwinii ocorre como epífita, em florestas de igapó e de terra firme.

Microgramma megalophylla (Desv.) de la Sota.

Fig. 6g-h

Material examinado selecionado: Menezes et al. 289 (UPCB).

Microgramma megalophylla ocorre como epífita, em florestas de igapó.

Microgramma nana (Liebm.) T.E. Almeida.

Fig. 6o-p

Material examinado: Menezes \& Nascimento Filho 212 (INPA).

Microgramma nana ocorre como epífita, em florestas de igapó.

Microgramma percussa (Cav.) de la Sota.

Fig. 6i-j

Material examinado selecionado: Menezes \& Nascimento 94 (INPA).

Microgramma percussa ocorre como epífita, em florestas de igapó e de terra firme.

Microgramma persicariifolia (Schrad.) C.Presl, Tent. Pterid. 214. 1836. Fig. 6k-1

Material examinado: Menezes et al. 274 (UPCB).

Microgramma persicariifolia ocorre como epífita, em florestas de igapó.
Microgramma reptans (Cav.) A.R.Sm., Proc. Calif. Acad. Sci. ser. 4, 40: 230. $1975 . \quad$ Fig. 6m-n Material examinado selecionado: Menezes et al. 312 (UPCB).

Microgramma reptans ocorre como epífita, em florestas de igapó e de terra firme.

Pecluma plumula (Willd.) M.G.Price. Fig. 6q-r Material examinado selecionado: Menezes et al. 316 (UPCB).

Pecluma plumula ocorre como epífita, em florestas de igapó e de terra firme.

Phlebodium decumanum (Willd.) J.Sm.

Fig. $6 \mathrm{~s}-\mathrm{t}$

Material examinado selecionado: Menezes et al. 337 (UPCB).

Phlebodium decumanum ocorre como epífita e rupícula, em florestas de igapó.

Pleopeltis desvauxii (Klotzsch) Salino.

Fig. 7a-b

Material examinado: Menezes \& Nascimento 100 (INPA).

Pleopeltis desvauxii ocorre como epífita, em florestas de igapó.

Serpocaulon triseriale (Sw.) A.R.Sm. Fig. 7c-d Material examinado: Menezes \& Nascimento 253 (INPA).

Serpocaulon triseriale ocorre como rupícola, em florestas de igapó. 



Figura 7 - a-b. Pleopeltis desvauxii - a. hábito; b. lâmina fértil. c-d. Serpocaulon triseriale - c. lâmina fértil; d. disposição dos soros e das nervuras (superfície abaxial). e-f. Adiantum argutum - e. hábito; f. pseudoindúsio glabro. g-h. A. cinnamomeum - g. hábito; h. soros. i-j. A. dolosum - i. disposição das pinas; j. base da pina. k-1. A. glaucescens - k. fronde; 1. porção acroscópica das pínulas sobrepondo a raque. m-n. A. latifolium - m. hábito; n. superfície abaxial glabra. o-p. A. lucidum - o. hábito; p. soros marginais contínuos. q-s. A. multisorum - q. hábito; r. escamas da raque; s. pínulas medianas com soros em ambas as margens e no ápice. t. A. obliquum - hábito.

Figure 7 - a-b. Pleopeltis desvauxii - a. habit; b. fertile lamina. c-d. Serpocaulon triseriale - c. fertile lamina; d. sori and veins. e-f. Adiantum argutum - e. habit; f. pseudo-indusium. g-h. A. cinnamomeum - g. habit; h. sori. i-j. A. dolosum - i. pinnae arrangment; j. pinna base. k-1. A. glaucescens - k. frond; 1. pinna base overlapping the rachis. $\mathrm{m}-\mathrm{n}$. A. latifolium - $\mathrm{m}$. habit; $\mathrm{n}$. abaxial surface of a pinna. o-p. A. lucidum - o. habit; p. continuous marginal sori. q-s. A. multisorum - q. habit; r. Scales from the rachis; s. medial pinnules showing the sori on both sides. t. A. obliquum - habit. 
Pteridaceae E.D.M.Kirchn.

\section{Chave de identificação dos gêneros de Pteridaceae}

1. Esporângios marginais, protegidos pela margem revoluta da lâmina (pseudoindúsios) .........Adiantum

1'. Esporângios ao longo das nervuras ou, se marginais, nunca protegidos pela margem revoluta da lâmina.

2. Lâmina pinada, lobada ou furcada; nervuras livres.

3. Plantas epífitas ou rupícolas; lâmina lobada ou furcada; esporângios situados sobre as nervuras..... Hecystopteris

3'. Plantas terrícolas; lâmina pinada; esporângios esparsos sobre o tecido laminar

Pityrogramma

2'. Lâmina inteira; nervuras anastomosadas.

4. Nervuras formando apenas uma linha de aréolas de cada lado da costa; tecido lâminar com menos de $0,5 \mathrm{~cm}$ larg. Vittaria

4'. Nervuras formando mais de uma linha de aréolas de cada lado da costa; tecido laminar com mais de $1 \mathrm{~cm}$ de larg.

5. Soros localizados apenas nas proximidades da margem da lâmina, submarginais, em apenas uma linha Ananthacorus

5'. Soros distribuídos por toda a superfície da lâmina, medianos, formando várias linhas ao longo das nervuras. Polytaenium

\section{Chave de identificação das espécies de Adiantum}

1. Frondes 1-pinada; soros contínuos ao longo da margem da lâmina, se 2-pinada, os soros interrompidos ao longo da margem laminar.

2. Soros interrompidos ao longo da margem do segmento Adiantum petiolatum

2'. Soros contínuos ao longo da margem do segmento.

3. Últimos segmentos com base simétrica

3'. Últimos segmentos com base assimétrica. Adiantum dolosum Adiantum lucidum

1'. Frondes 2-pinada ou mais divididas; soros descontínuos ao longo da margem laminar.

4. Idioblastos ausentes em ambas as faces do tecido laminar.... Adiantum tomentosum

4'. Idioblastos presentes em uma ou ambas as faces do tecido laminar

5. Raque glabra.

5'. Raque escamosa e/ou pilosa

6. Pseudoindúsio glabro

7. Pínulas esparsas, com ápice acuminado; face abaxial das pinas não glauca, pilosa e com idioblastos..... Adiantum argutum

7’. Pínulas imbricadas, com ápice arredondado; face abaxial das pinas glauca, glabra e sem idioblastos Adiantum latifolium

6'. Pseudoindúsio com indumento.

8. Pina terminal 1,5 a 2 vezes mais longa que as laterais Adiantum obliquum

8'. Pina terminal aproximadamente do mesmo tamanho que as laterais.

9. Pinas com 35 ou mais pares de pínulas por pina, raque densamente escamosa.

10. Pínulas $3 \mathrm{x}$ mais compridas que largas; soros restritos ao lado acroscópico nas pínulas medianas. Adiantum cinnamomeum

10'. Pínulas 2x mais compridas que largas; soros distribuídos no lado acroscópico e apical, por vezes no lado basioscópico, nas pínulas medianas..... Adiantum multisorum

9'. Pinas com menos que 35 pares de pínulas, raque moderadamente escamosa.

11. Epiderme abaxial com escamas filiformes de base inteira Adiantum terminatum

11'. Epiderme abaxial com escamas linear-lanceoladas de base pectinada.

12. Pínulas retangulares, últimos segmentos estéreis com ápice arredondado Adiantum paraense 
12'. Pínulas geralmente falcadas, últimos segmentos estéreis com ápice acuminado a obtuso

Adiantum argutum Splitg.

Fig. 7e-f

Material examinado selecionado: Menezes et al. 279 (UPCB).

Adiantum argutum ocorre como terrícola, florestas de igapó e de terra firme.

Adiantum cinnamomeum Lellinger \& J.Prado.

Fig. $7 \mathrm{~g}-\mathrm{h}$

Material examinado selecionado: Menezes et al. 311 (UPCB).

Adiantum cinnamomeum ocorre como terrícola, em florestas de terra firme.

Adiantum dolosum Kunze.

Fig. 7i-j

Material examinado: Menezes \& Nascimento 132 (INPA).

Adiantum dolosum ocorre como terrícola, em florestas de terra firme.

Adiantum glaucescens Klotzsch.

Fig. 7k-1 Material examinado selecionado: Menezes \& Nascimento Filho 199 (INPA).

Adiantum glaucescens ocorre como terrícola, em ambientes antropizados.

Adiantum latifolium Lam.

Fig. $7 \mathrm{~m}-\mathrm{n}$

Material examinado selecionado: Menezes et al. 277 (UPCB).

Adiantum latifolium ocorre como terrícola em ambientes antropizados, florestas de igapó e de terra firme.

Adiantum lucidum (Cav.) Sw.

Fig. 7o-p Material examinado: Menezes \& Nascimento 130 (INPA).

Adiantum lucidum ocorre como terrícola, em florestas de terra firme.

Adiantum multisorum A.Samp.

Fig. 7q-s Material examinado selecionado: Menezes \& Nascimento 233 (INPA).

Adiantum multisorum ocorre como terrícola, em florestas de terra firme.

Adiantum obliquum Willd.

Figs. 7t; $8 \mathrm{a}$

Material examinado selecionado: Menezes \& Nascimento Filho 340 (UPCB).

Adiantum obliquum ocorre como terrícola, em florestas de igapó e de terra firme.
Adiantum paraense Hieron.

Fig. $8 b-c$ Material examinado selecionado: Menezes et al. 339 (UPCB).

Adiantum paraense ocorre como terrícola, em florestas de terra firme.

Adiantum petiolatum Desv.

Fig. 8d-e

Material examinado selecionado: Menezes et al. 338 (UPCB).

Adiantum petiolatum ocorre como rupícola e terrícola, em florestas de igapó.

Adiantum terminatum Kunze ex Miq. Fig. 8f-g Material examinado selecionado: Menezes et al. 305 (UPCB).

Adiantum terminatum ocorre como terrícola, em florestas de igapó e de terra firme.

Adiantum tetraphyllum Humb. \& Bonpl. ex Willd.

Fig. $8 \mathrm{~h}-\mathrm{j}$ Material examinado selecionado: Menezes et al. 299 (UPCB).

Adiantum tetraphyllum ocorre como terrícola, em florestas de terra firme.

Adiantum tomentosum Klotzsch. Fig. 8k-m Material examinado: Menezes \& Almeida 329 (HSTM,UPCB).

Adiantum tomentosum ocorre como terrícola, em florestas de igapó.

Ananthacorus angustifolius (Sw.) Underw. \& Maxon.

Fig. 8n-o

Material examinado: Menezes \& Nascimento Filho 215 (INPA).

Ananthacorus angustifolius ocorre como epífita, em florestas de igapó.

Hecistopteris pumila (Spreng.) J.Sm. Fig. 8p Material examinado: Menezes \& Nascimento Filho 210 (INPA).

Hecistopteris pumila ocorre como epífita, em florestas de terra firme.

Pityrogramma calomelanos (L.) Link var. calomelanos.

Fig. 8q-r

Material examinado selecionado: Menezes \& André 332 (UPCB).

Pityrogramma calomelanos ocorre como terrícola, em florestas de igapó. 

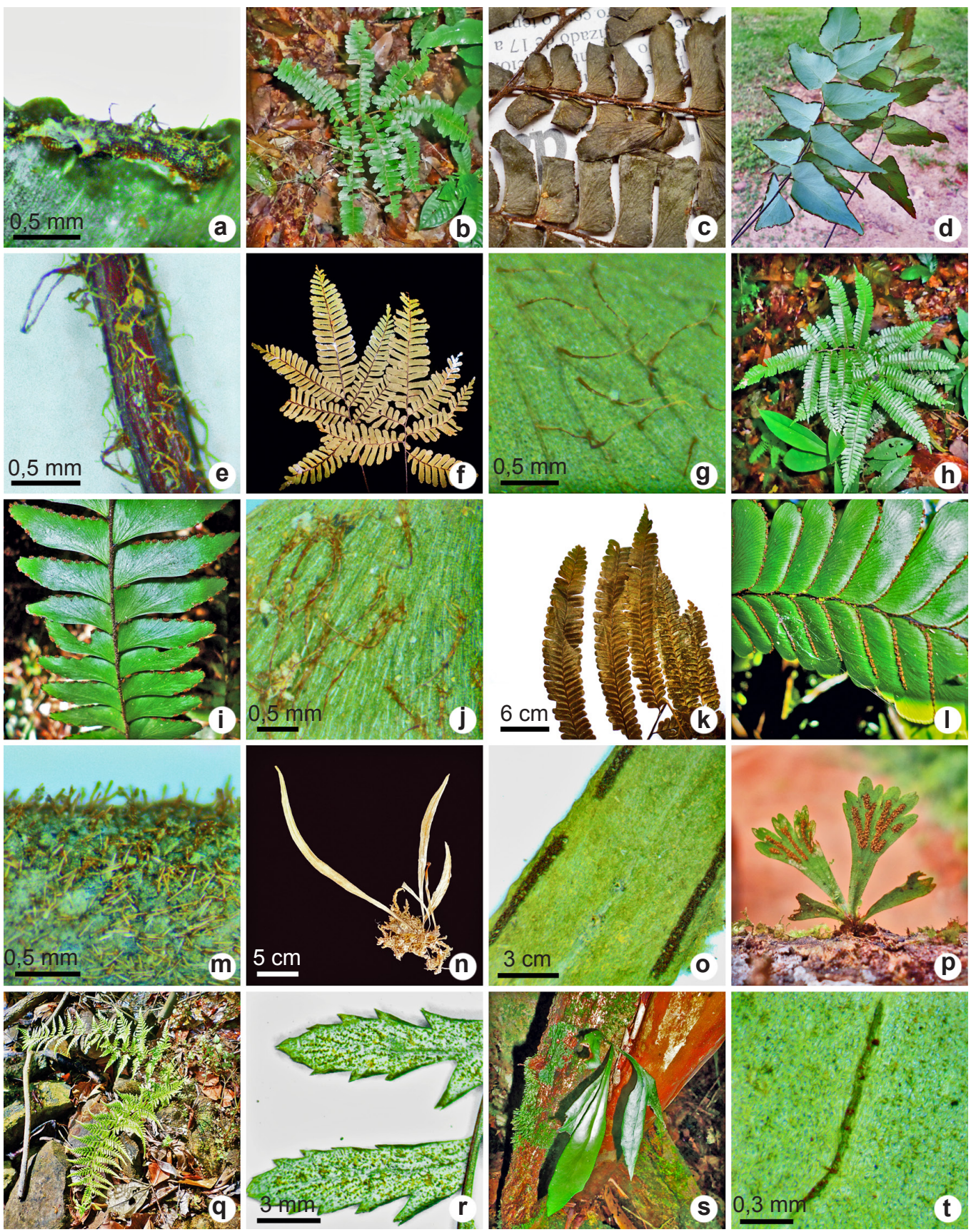

Figura 8 - a. A. obliquum - indúsio com tricoma. b-c. A. paraense - b. hábito; c. pínulas com ápice arredondado. d-e. A. petiolatum - d. hábito; e. raque com escamas e tricomas. f-g. A. terminatum - f. pinas (superfície abaxial); g. escamas filiformes (superfície abaxial). h-j. A. tetraphyllum - h. hábito; i. pínulas; j. indumento com escamas de base pectinada (superfície abaxial). k-m. A. tomentosum - k. pinas; 1. pínulas imbricadas; m. raque com tricomas (superfície abaxial). n-o. Ananthacorus angustifolius - n. frondes; o. epiderme abaxial. p. Hecistopteris pumila hábito. q-r. Pityrogramma calomelanos var. calomelanos - q. hábito; r. epiderme abaxial das pínulas. s-t. Polytaenium cajenense - s. hábito; t. soro sulcado, esporângios imersos na lâmina.

Figure 8 - a. Adiantum obliquum - indusium with hairs. b-c. A. paraense - b. habit; c. pinnules. d-e. A. petiolatum - d. habit; e. rachis showing hairs and scales. f-g. A. terminatum - f. abaxial side of the pinnules; g. filiform scales from the abaxial side of a pinnule. $\mathrm{h}-\mathrm{j}$. A. tetraphyllum - h. habit; i. pinnules; j. scales with pectinate bases. k-m. A. tomentosum - k. pinnae; 1. pinnules; m. abaxial side of a rachis showing the hairs. n-o. Ananthacorus angustifolius - n. habit; o. abaxial side of the lamina. p. Hecistopteris pumila - habit. q-r. Pityrogramma calomelanos var. calomelanos - q. habot; r. abaxial surface of a pinnule. s-t. Polytaenium cajenense - s. habit; t. sori. 
Chave de identificação das espécies de Polytaenium

1. Soros profundamente sulcados, esporângios imersos na lâmina Polytaenium cajenense

1'. Soros superficiais ou levemente sulcados, esporângios não imersos na lâmina Polytaenium guayanense

Polytaenium cajenense (Desv.) Benedict.

Fig. $8 \mathrm{~s}-\mathrm{t}$

Material examinado: Menezes et al. 285 (UPCB).

Polytaenium cajenense ocorre como epífita, em florestas de terra firme.

Polytaenium guayanense (Hieron.) Alston.

Fig. 9a-b

Material examinado selecionado: Menezes et al. 314 (UPCB).

Polytaenium guayanense ocorre como epífita, em florestas de terra firme.

Vittaria lineata (L.) Sm.

Fig. 9c-d

Material examinado: Menezes \& Nascimento 259 (INPA).

Vittaria lineata ocorre como rupícola, em florestas de igapó.
Saccolomataceae Doweld

Saccoloma inaequale (Kunze) Mett.

Fig. 9e-f

Material examinado: Menezes \& Nascimento 172 (INPA).

Saccoloma inaequale ocorre como terrícola, em florestas de terra firme.

Salviniaceae Martinov

Salvinia auriculata Aubl.

Fig. 9g-h

Material examinado: Menezes \& Nascimento 260 (INPA).

Salvinia auriculata ocorre como aquática, em florestas de igapó.

Schizaeaceae Kaulf.

\section{Chave de identificação dos gêneros de Schizaeaceae}

1. Esporangióforos digitados Actinostachys

1'. Esporangióforos pinados Schizaea

Actinostachys pennula (Sw.) Hook.

Fig. 9i-j

Material examinado selecionado: Menezes et al. 284 (UPCB).

Actinostachys pennula ocorre como terrícola, em ambientes antropizados.
Schizaea elegans (Vahl) Sw.

Fig. 9k-1

Material examinado: Menezes et al. 307 (UPCB).

Schizaea elegans ocorre como terrícola, em floresta de terra firme.

Tectariaceae Panigrahi

\section{Chave de identificação dos gêneros de Tectariaceae}

1. Nervuras anastomosadas Tectaria

1'. Nervuras livres Triplophyllum

Tectaria incisa Cav. Fig. $9 \mathrm{~m}-\mathrm{n}$ Material examinado selecionado: Menezes \& Nascimento 222 (INPA).
Tectaria incisa ocorre como terrícola, em florestas de igapó e de terra firme. 

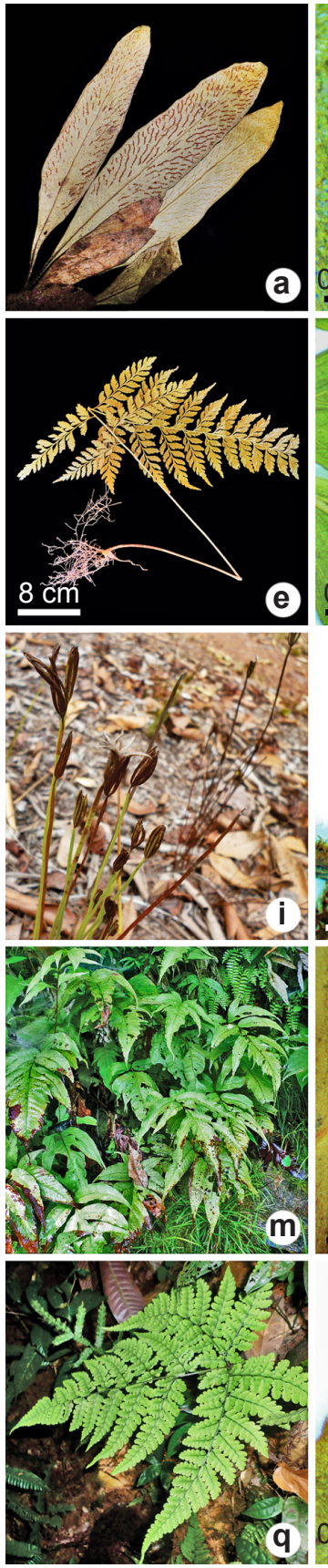
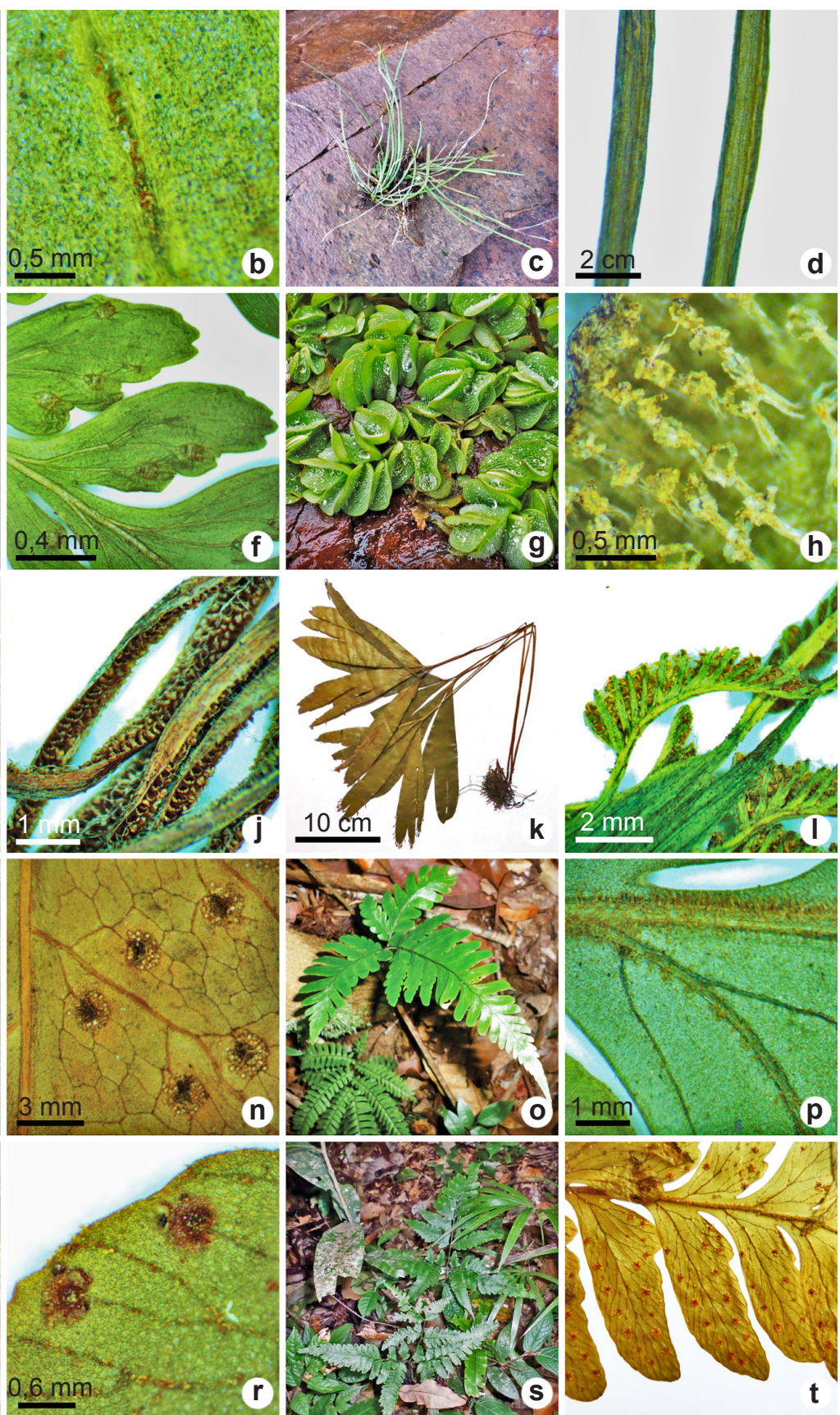

Figura 9 - a-b. Polytaenium guayanense - a. lâmina fértil; b. soros superficiais, esporângios não imersos na lâmina. c-d. Vittaria lineata - c. frondes; d. epiderme adaxial (à esq.) e abaxial (à dir.). e-f. Saccoloma inaequale - e. fronde; f. disposição dos soros. g-h. Salvinia auriculata - g. hábito; h. tricomas unidos na porção distal. i-j. Actinostachys pennula - i. hábito; j. esporangióforos digitados. k-1. Schizaea elegans - k. hábito; 1. esporangióforos pinados. m-n. Tectaria incisa $-\mathrm{m}$. hábito; $\mathrm{n}$. nervuras anastomosadas. o-p. Triplophyllum angustifolium $-\mathrm{o}$. hábito; $\mathrm{p}$. costa $\mathrm{e}$ cóstula puberulentos (superfície abaxial). q-r. T. dicksonioides - q. hábito; r. glândulas sobre nervuras, tecido laminar e indúsio. s-t. T. funestum - s. hábito; t. pínulas (epiderme abaxial).

Figure 9 - a-b. Polytaenium guayanense - a. fertile frond; b. sori with superficial sporangia. c-d. Vittaria lineata $-\mathrm{c}$. fronds; d. lamina surfaces. e-f. Saccoloma inaequale - e. habit; f. sori. g-h. Salvinia auriculata - g. habit; h. hairs. i-j. Actinostachys pennula - i. habit; j. sporangiophores. k-1. Schizaea elegans - k. frond; 1. sporangiophores. m-n. Tectaria incisa - m. habit; n. veins. o-p. Triplophyllum angustifolium - o. habit; $\mathrm{p}$. hairs on costa and costules. q-r. T. dicksonioides - q. habit; r. glandular hairs. s-t. T. funestum - s. habit; t. abaxial surface of a pinna. 
Chave de identificação das espécies de Triplophyllum

1. Margem das pinas não ciliada; indúsio glabro Triplophyllum glabrum

1'. Margem das pinas esparsamente ciliada; indúsio pubescente ou glandular.

2. Pinas basais aproximadamente equiláteras Triplophyllum angustifolium

2'. Pinas basais conspicuamente alongadas no lado basioscópico.

3. Indúsio não glandular. Triplophyllum dicksonioides

3'. Indúsio glandular. Triplophyllum funestum

Triplophyllum angustifolium Holttum.

Triplophyllum funestum (Kunze) Holttum.

Fig. $90-p$

Material examinado selecionado: Menezes et al. 304 (UPCB).

Triplophyllum angustifolium ocorre como terrícola, em florestas de igapó.

Triplophyllum dicksonioides (Fée) Holttum.

Fig. 9q-r

Material examinado selecionado: Menezes et al. 296 (UPCB).

Triplophyllum dicksonioides ocorre como terrícola, em florestas de terra firme.

$$
\begin{array}{r}
\text { Fig. } 9 \mathrm{~s}-\mathrm{t} \\
\text { Material examinado selecionado: Menezes et al. } 320
\end{array}
$$
(UPCB).

Triplophyllum funestum ocorre como terrícola, em florestas de terra firme.

Triplophyllum glabrum J.Prado \& R.C.Moran.

Fig. 10a-b

Material examinado selecionado: Menezes \& André 331 (UPCB).

Triplophyllum glabrum ocorre como terrícola, em florestas de terra firme.

Thelypteridaceae Ching ex Pic.Serm.

\section{Chave de identificação dos gêneros de Thelypteridaceae}

1. Tricomas furcados a estrelados presentes ao menos sobre a raque e costa; tricomas glandulares ausentes Goniopteris

1'. Tricomas furcados a estrelados ausentes; tricomas glandulares ausentes ou presentes.

2. Lâmina 1-pinada, nervuras regularmente anastomosadas...............................................eniscium

2'. Lâmina 1-pinado-pinatífida, nervuras livres Cyclosorus

Cyclosorus interruptus (Willd.) H.Itô. Fig. 10c-d Material examinado selecionado: Menezes \& Nascimento 249 (INPA).

Cyclosorus interruptus ocorre como aquática, em florestas de igapó.
Goniopteris tristis (Kunze) Brade. $\quad$ Fig. 10e-f Material examinado: Menezes \& Nascimento 221 (INPA).

Goniopteris tristis ocorre como terrícola, em florestas de terra firme.

\section{Chave de identificação das espécies de Meniscium}

1. Margem das pinas serrada em toda sua extensão.

Meniscium serratum

1. Margem das pinas inteiras, ou serradas apenas no ápice Meniscium longifolium

Meniscium longifolium Desv.

Fig. 10g-h Material examinado selecionado: Menezes \& Nascimento Filho 216 (INPA).

Meniscium longifolium ocorre como terrícola, em ambientes antropizados e em florestas de igapó.
Meniscium serratum Cav.

Material examinado: Menezes \& Almeida 325 (UPCB). Meniscium serratum ocorre como terrícola, em florestas de igapó. 

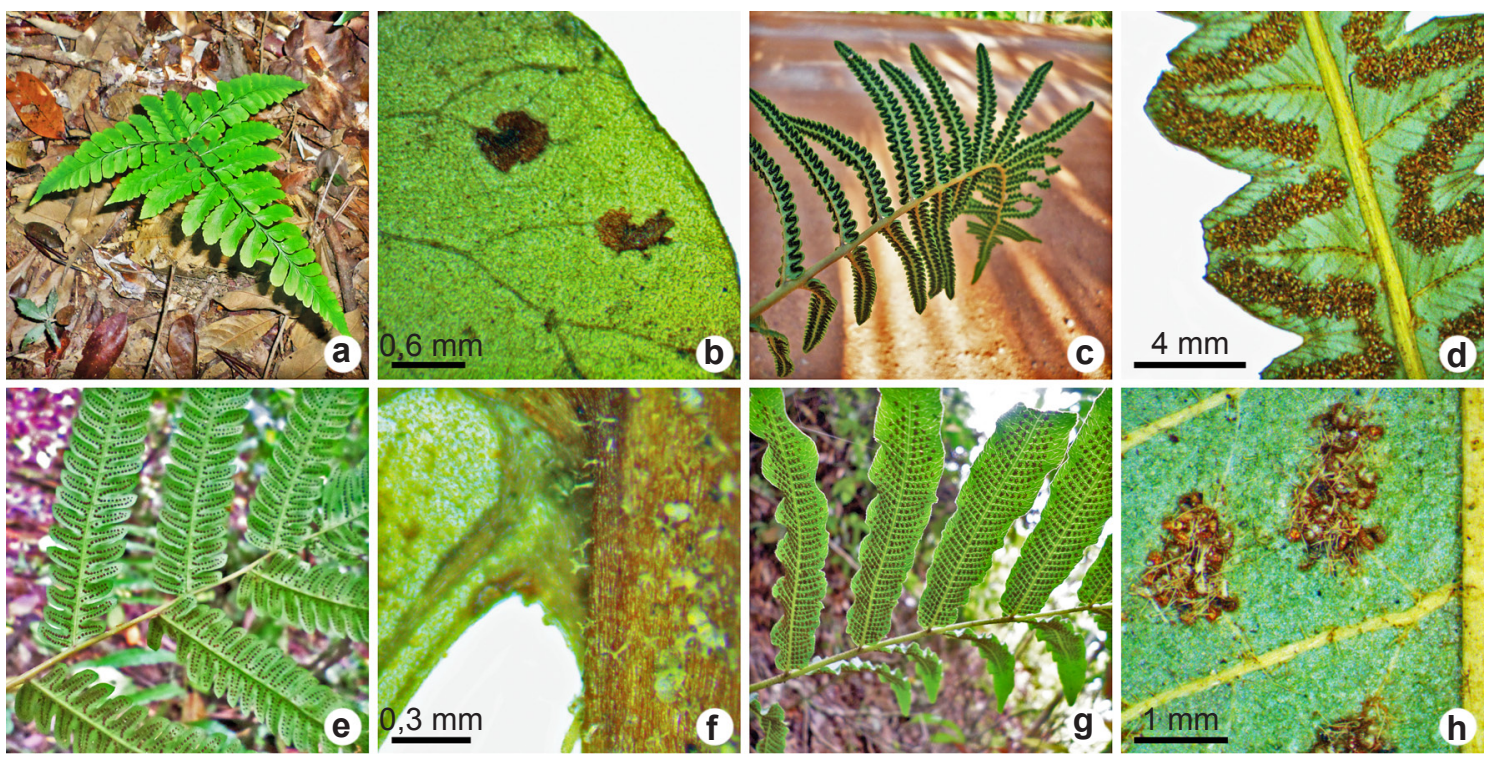

Figura 10 - a-b. Triplophyllum glabrum - a. hábito; b. tecido laminar e indúsio. c-d. Cyclosorus interruptus - c. pínulas; d. disposição dos soros e das nervuras. e-f. Goniopteris tristis - e. raque porção basal das pinas (face abaxial); f. tricomas furcados (superfície abaxial). g-h. Meniscium longifolium - g. pínulas; h. disposição das nervuras (face abaxial).

Figure 10 - a-b. Triplophyllum glabrum - a. habit; b. laminar tissue and indusia. c-d. Cyclosorus interruptus - c. pinnules; d. sori and veins. e-f. Goniopteris tristis - e. abaxial side of a rachis; f. hairs from the abaxial side of the lamina. $\mathrm{g}-\mathrm{h}$. Meniscium longifolium - $\mathrm{g}$. pinnae; h. veins.

\section{Agradecimentos}

Agradecemos ao curso de Pós-graduação em Botânica do INPA e à FAPEAM, a bolsa de Mestrado concedida ao primeiro autor; e ao CNPQ, a bolsa de Produtividade concedida a P.H.L. (proc. 307514/2016-1). Agradecemos ao Departamento de Botânica da UFPR, onde parte dos estudos foram realizados. Agradecemos também ao Dr. Jefferson Prado, a identificação dos espécimes de Adiantum; ao Dr. Fernando B. de Matos e à Dra. Thais Almeida, o auxílio nas atividades de campo e na identificação de alguns dos materiais; e a dois revisores anônimos, as sugestões ao texto. Agradecemos também ao ICMBio, a permissão de coleta e a infraesturura disponibilizada.

\section{Referências}

Alvares CA, Stape JL, Sentelhas PC, Gonçalves JLM \& Sparovek G (2013) Köppen's climate classification map for Brasil. Meteorologische Zeitschrift 22: 711-728.

Costa JM \& Pietrobom MR (2007) Pteridófitas (Lycophyta e Monilophyta) da Ilha de Mosqueiro, Município de Belém, estado do Pará, Brasil. Boletim do Museu Paraense Emílio Goeldi, Ciências Naturais 2: $45-55$.
Costa JM \& Pietrobom MR (2010) Samambaias e Licófitas do Parque Ecológico do Gunma, Município de Santa Bárbara do Pará, estado do Pará, Brasil. Rodriguésia 61: 223-232.

Costa MAS \& Prado J (2005a) Flora da Reserva Ducke, Amazonas, Brasil: Pteridophyta - Metaxyaceae. Rodriguésia 56: 72-73.

Costa MAS \& Prado J (2005b) Flora da Reserva Ducke, Amazonas, Brasil: Pteridophyta - Ophioglossaceae. Rodriguésia 56: 74-75.

Freitas CAA \& Prado J (2005a) Flora da Reserva Ducke, Amazonas, Brasil: Pteridophyta - Dryopteridacae. Rodriguésia 56: 49-52.

Freitas CAA \& Prado J (2005b) Lista anotada das pteridófitas de florestas inundáveis do alto Rio Negro, Município de Santa Isabel do Rio Negro, AM, Brasil. Acta Botanica Brasilica 19: 399-406.

Freitas CAA \& Windisch PG (2005) Flora da Reserva Ducke, Amazonas, Brasil: Pteridophyta Lycopodiaceae. Rodriguésia 56: 67-68.

Góes-Neto LAA, Pallos J \& Salino A (2016) Flora das Cangas da Serra dos Carajás, Pará, Brasil: Selaginellaceae. Rodriguésia 67: 1177-1180.

Haufler CH, Pryer KM, Schuettpelz E, Sessa EB, Farrar DR, Moran RC, Schneller JJ, Watkins JE \& Windham MD (2016) Sex and the single gametophyte: revising the homosporous vascular plant life cycle in light of contemporary research. BioScience 66: 928-937. 
Hopkins MJG (2007) Modelling the known and unknown plant biodiversity of the Amazon Basin. Journal of Biogeography 34: 1400-1411.

IBDF (1978) Plano de Manejo do Parque Nacional da Amazônia (Tapajós). MMA / IBDF / Polamazônia, Brasília. 168p.

Kasecker T \& Silva JMC (2011) Parque Nacional da Amazônia. In: Valente RM, Silva JMC, Straube FC \& Nascimento JLX (orgs.) Conservação de aves migratórias neárticas no Brasil. Conservação Internacional, Belém. Pp. 92-95.

Kessler M (2010) Biogeography of Ferns. In: Mehltreter K, Walker LR \& Sharpe JM (orgs.) Fern ecology. Cambridge University Press, Cambridge. Pp. 22-60.

Lellinger DB (2002) A modern multilingual glossary for taxonomic pteridology. American Fern Society, Washington. 264p.

Maciel S, Souza MGC \& Pietrobom MR (2007) Licófitas e monilófitas do Bosque Rodrigues Alves Jardim Botânico da Amazônia, Município de Belém, estado do Pará, Brasil. Boletim do Museu Paraense Emílio Goeldi, Ciências Naturais 2: 69-83.

Martinelli G \& Moraes MA (2013). Livro Vermelho da Flora do Brasil. Instituto de Pesquisas Jardim Botânico do Rio de Janeiro, Rio de Janeiro. Pp. 1-1100.

Moran RC (2008) Diversity, biogeography, and floristics. In: Ranker TA \& Haufler CH (eds.) Biology and evolution of Ferns and Lycophytes. Cambridge University Press, Cambridge. Pp. 367-394.

Moura IO, Arruda AJ \& Salino A (2016a) Flora das Cangas da Serra dos Carajás, Pará, Brasil: Aspleniaceae. Rodriguésia 67: 1141-1144.

Moura IO \& Salino A (2016a) Flora das Cangas da Serra dos Carajás, Pará, Brasil: Dryopteridaceae. Rodriguésia 67: 1151-1157.

Moura IO \& Salino A (2016b) Flora das Cangas da Serra dos Carajás, Pará, Brasil: Pteridaceae. Rodriguésia 67: 1167-1175.

Moura LC, Arruda AJ \& Salino A (2016b) Flora das Cangas da Serra dos Carajás, Pará, Brasil: Thelypteridaceae. Rodriguésia 67: 1181-1189.

PPG I (2016) A community-derived classification for extant Lycophytes and Ferns. Journal of Sysematics and Evolution 54: 463-603.

Prado J (2005a) Flora da Reserva Ducke, Amazonas, Brasil: Pteridophyta. Chave para as famílias. Rodriguésia 56: 27-28.

Prado J (2005b) Flora da Reserva Ducke, Amazonas, Brasil: Pteridophyta - Aspleniaceae. Rodriguésia 56: 29-32.

Prado J (2005c) Flora da Reserva Ducke, Amazonas, Brasil: Pteridophyta - Blechnaceae. Rodriguésia 56: 33-34.

Prado J (2005d) Flora da Reserva Ducke, Amazonas, Brasil: Pteridophyta - Davalliaceae. Rodriguésia 56: $38-42$.

Prado J (2005e) Flora da Reserva Ducke, Amazonas,
Brasil: Pteridophyta - Grammitidaceae. Rodriguésia 56: $56-58$.

Prado J (2005f) Flora da Reserva Ducke, Amazonas, Brasil: Pteridophyta - Marattiaceae. Rodriguésia 56: 69-71.

Prado J (2005g) Flora da Reserva Ducke, Amazonas, Brasil: Pteridophyta - Tectariaceae. Rodriguésia 56: 103-104.

Prado J (2005h) Flora da Reserva Ducke, Amazonas, Brasil: Pteridophyta - Thelypteridaceae. Rodriguésia 56: 105-107.

Prado J (2005i) Flora da Reserva Ducke, Amazonia, Brasil: Pteridophyta - Dennstaedtiaceae. Rodriguésia 56: 43-48.

Prado J (2005j) Flora da Reserva Ducke, Amazonia, Brasil: Pteridophyta - Gleicheniaceae. Rodriguésia 56: 53-55.

Prado J (2005k) Flora da Reserva Ducke, Amazonia, Brasil: Pteridophyta - Lomariopsidaceae. Rodriguésia 56: 59-66.

Prado J (20051) Flora da Reserva Ducke, Amazônia, Brasil: Pteridophyta - Polypodiaceae. Rodriguésia 56: 76-84.

Prado J (2005m) Flora da Reserva Ducke, Amazônia, Brasil: Pteridophyta - Pteridaceae. Rodriguésia 56: 85-92.

Prado J (2005n) Flora da Reserva Ducke, Amazônia, Brasil: Pteridophyta - Schizaeaceae. Rodriguésia 56: 93-97.

Prado J \& Freitas CAA (2005a) Flora da Reserva Ducke, Amazonas, Brasil: Pteridophyta - Selaginellaceae. Rodriguésia 56: 98-102.

Prado J \& Freitas CAA (2005b) Flora da Reserva Ducke, Amazonas, Brasil: Pteridophyta - Cyatheaceae. Rodriguésia 56: 35-37.

Prado J \& Labiak PH (2005) Flora da Reserva Ducke, Amazônia, Brasil: Pteridophyta - Vittariaceae. Rodriguésia 56: 85-92.

Prado J, Sylvestre LS, Labiak PH, Windisch PG, Salino A, Barros ICL, Hirai RY, Almeida TE, Santiago ACP, Kieling-Rubio MA, Pereira AFN, Øllgaard B, Ramos CGV, Mickel JT, Dittrich VAO, Mynssen CM, Schwartsburd PB, Condack JPS, Pereira JBS \& Matos FB (2015) Diversity of Ferns and Lycophytes in Brazil. Rodriguésia 66: 1073-1083.

Prance GT (1980) A terminologia dos tipos de florestas amazônicas sujeitas a inundação. Acta Amazonica 10: 495-504.

Pryer KM, Eric S, Wolf PG, Schneider H, Smith AR \& Cranfill R (2004) Phylogeny and evolution of Ferns (Monilophytes) with a focus on the early leptosporangiate divergences. American Fern Journal 91: 1582-1598.

Rodrigues ST, Almeida SS, Andrade LHC, Barros ICL \& Berg ME (2004) Composição florística e abundância de Pteridófitas em três ambientes da Bacia do Rio Guamá, Belém, Pará, Brasil. Acta Amazonica 34: 35-42. 
Salino A \& Arruda AJ (2016a) Flora das Cangas da Serra dos Carajás, Pará, Brasil: Cyatheaceae. Rodriguésia 67: 1145-1147.

Salino A \& Arruda AJ (2016b) Flora das Cangas da Serra dos Carajás, Pará, Brasil: Dennstaedtiaceae. Rodriguésia 67: 1149-1150.

Salino A \& Arruda AJ (2016c) Flora das Cangas da Serra dos Carajás, Pará, Brasil: Lycopodiaceae. Rodriguésia 67: 1159-1161.

Salino A \& Arruda AJ (2016d) Flora das Cangas da Serra dos Carajás, Pará, Brasil: Lygodiaceae. Rodriguésia 67: 1163-1164.

Salino A \& Arruda AJ (2016e) Flora das Cangas da Serra dos Carajás, Pará, Brasil: Oleandraceae. Rodriguésia 67: 1165-1166.

Salino A, Arruda AJ \& Almeida TE (2018). Ferns and Lycophytes from Serra dos Carajás, an Eastern Amazonian mountain range. Rodriguésia 69: 14171434.
SEMAS (2018) Espécies Ameaçadas. Governo do estado do Pará / Secretaria de Meio Ambiente e Sustentabilidade. Disponível em <https:/www. semas.pa.gov.br/2009/03/27/9439/>. Acesso em 29 novembro 2018.

Travassos CC, Jardim MAG \& Maciel S (2014) Florística e ecologia de Samambaias e Licófitas como indicadores de conservação ambiental. Biota Amazônica 4: 40-44.

Tryon RM \& Conant DS (1975) The Ferns of Brazilian Amazonia. Acta Amazonica 5: 23-34.

Tryon RM \& Tryon AF (1982) Ferns and allied plants. Springer-Verlag, Cambridge. Pp. 1-857.

Watkins Jr JE, Cardelús C, Colwell RK \& Moran RC (2006) Species richness and distribution of ferns along an elevational gradient in Costa Rica. American Journal of Botany 93: 73-83.

Zuquim G, Costa FRC, Prado J \& Tuomisto H (2008) Guia de Samambaias e Licófitas da REBio Uatumã - Amazônia Central. Attema, Manaus. 316p. 